\title{
Cmambu
}

\section{КРЕАТИВНОСТЬ И ДЕВИАНТНОСТЬ: СВЯЗЬ И ВЗАИМОДЕЙСТВИЕ}

\author{
Н.В. МЕШКОВА ${ }^{a}$, С.Н. ЕНИКОЛОПОВ
}

"ФГБОУ ВО «Московский государственный психолого-педагогиеский университет», 127051, Россия, Москва, ул. Сретенка, д. 27.

${ }^{5}$ Федеральное государственное бюджетное науиное уиреждение «Научный центр психического здоровья», 115522, Россия, Москва, Каширское шоссе, д. 34

\begin{abstract}
Резюме
В статье анализируются теории, конщепции и результаты исследований креативности, которые могут быть полезны для понимания причин связи девиантного поведения и креативности. Приводятся особенности социально-креативной личности: неформальное лидерство; высокие значения эмоционального интеллекта, когнитивной и аффективной эмпатии и поиска новизны; низкий уровень зависимости от вознаграждения; гибкие моральные границы; макиавеллизм, умение манипулировать другими для достижения собственных целей; разумное сочетание әгоизма и альтруизма. Рассматриваются подходы к пониманию креативного потенциала и оценке компонентов, его составляюцих, а также личностные и ситуативњые характеристики, способствуюцие реализации креативного потенциала для нанесения вреда другим людям. В качестве личностных характеристик, способствующих реализации креативного потенциала в девиантном поведении, для дальнейшего исследования выделяются враждебность и эмоциональный интеллект. Анализируются проблемы, касающиеся изучения реализации креативного потенциала в девиантном поведении. На основе теории креативной девиантности (C. Mainemelis) предложена комплексная модель креативности и девиантности. Модель объединяет следующие параметры: креативный потенциал разработчика, характеристики исполнителей, цели, условия и способы достижения цели, результат. В модели учитывается модальность целей, способов и результатов креативного процесса, а также мишень нанесенного вреда. Особенность модели состоит в том, что ее можно применять для анализа и изучения антисоциальной креативности как отдельных индивидов, так и групп. В рамках модели выделяются четыре вида креативности. Дается определение терминам «девиантная креативность», «антисоциальная/асоциальная» креативность, «негативная креативность» и «креативная девиантность».
\end{abstract}

Ключевые слова: креативность, девиантность, креативная девиантность, антисоциальная креативность, комплексная модель креативности и девиантности.

Исследование выполнено при финансовой поддержке РФФИ в рамках научного проекта № 17-06-00608-ОГН «Личностные и ситуативные особенности асоциальной и негативной креативности». 


\section{Введение и состояние проблемы}

Креативность представляет собой феномен, интерес к которому со стороны психологов вызван изучением процесса, условий и психологических характеристик, обусловливающих разработку и внедрение новых и эффективных продуктов и идей, приносящих благо обществу и направленных на решение проблем, возникающих в различных областях деятельности человека. За более чем вековой период исследований креативности в центре внимания зарубежных психологов находились процесс и стадии дивергентного/творческого мышления (Дж. Гилфорд; Е. Торранс); продукт (А. и Д. Кропли), являющийся результатом творческого мышления; характеристики личности креативных людей (Т. Любарт, Р. Стернберг) и среды (Т. Амабиле), способствующей или мешающей реализации и развитию креативности. В отечественной психологии феномен активно изучался у детей и подростков учашихся школ различного профиля в рамках дифференциальной психологии (В.Н. Дружинин), деятельностного подхода (А.Н. Воронин) и с фокусом внимания на стадиях творческого процесса при решении интеллектуальных задач (Д.Б. Богоявленская, Я.А. Пономарев).

Анализируя феномен, M. Родес (Rhodes 1961) более полувека назад ввел аббревиатуру «4Р» креативности по первым буквам английского эквивалента компонентов «продукт», «процесс», «личность», «среда». «Покомпонентное» изучение креативности привело к появлению большого количества подходов и теорий. Отметим, что, хотя при этом существенно расширяется спектр переменных и факторов, помогающих анализу и диагностике креативности, а также прогнозированию успешности личности в дальнейшей профессиональной деятельности, единого понимания феномена креативности среди психологов не возникло. Данное обстоятельство можно объяснить, несколькими причинами. Во-первых, на понимание термина «креативность» оказывает влияние культурный контекст (Westwood, Low, 2003; Kharkhurin, 2014). Вовторых, о знаниях, полученных в одной области изучения креативности, почти не известно исследователям других областей (Hennessey, Amabile, 2010). В-третьих, не решена проблема о том, насколько креативность является универсальным феноменом или имеет специфические особенности в различных областях деятельности человека (Baer, 2010; Julmi, Scherm, 2015).

Остается малоизученной проблема использования творческого мышления в тех случаях, когда достижение собственной цели индивидом приводит к нанесению намеренного вреда другим людям или объектам, т.е. к агрессии (Ениколопов, 2010). В данном случае речь идет об антисоциально направленной креативности, проявляющейся в терроризме, мошенничестве, буллинге, вандализме. Особенность перечисленных видов деятельности и актов поведения состоит в том, что в большинстве случаев «творцом» и «реализатором» идеи является не один и тот же человек, что затрудняет понимание механизмов возникновения и реализации негативных явлений креативности и подготовку превентивных мероприятий (Мешкова, Ениколопов, 2016б). Затрудняется изучение феномена еще и тем фактом, что, во-первых, количество таких людей 
не слишком велико, а, во-вторых, попавшихся в руки правосудия креативных преступников слишком мало. Кроме того, очень часто они являются социально адаптированными людьми, что, в свою очередь, затрудняет их выявление. Однако, как справедливо полагают А. и Д. Кропли, игнорирование особенностей креативного меньшинства и оценка его правонарушений по тем же параметрам, что и не креативного большинства, не оправданны (Cropley, Cropley, 2011). События реальной жизни демонстрируют, что у проблемы терроризма и групповой преступности (мошенники, воры, грабители банков и т.д.) есть две стороны: первая - креативность лидера и его решения, вторая - принятие и осуществление этих решений членами группы. Понятно, что при разработке превентивных мероприятий следует понимать, с кем предстоит иметь дело.

\section{Креативный потенциал: компоненты и условия реализации}

Дискуссии относительно универсальности и специфичности креативности не могли не затронуть проблему креативного потенциала. На настоящий момент многие исследователи согласны с тем, что креативность является многомерным конструктом, включающим набор способностей и черт, оптимальная комбинация которых варьируется в зависимости от области активности и задачи, для решения которой привлекаются творческие peсурсы (Barbot et al., 2016). К ресурсам относятся интеллектуальные способности, знания в определенной области, когнитивные стили, личность, ее мотивация и эмоции, физический и социокультурный контекст (Caroff, Lubart, 2012), качественное и количественное соотношение которых и составляет креативный потенциал (Corazza, 2016).

Коллектив авторов под руководством Б. Барбот предложил аналитикокомпонентый подход к оценке креативного потенциала. Суть подхода состоит в том, чтобы на основе анализа задачи выявить необходимые для ее решения ресурсы, а затем составить профиль креативности, включающий оптимальное для решения задачи соотношение характеристик. Оптимальный профиль сравнивается с реальным профилем индивида с помощью статистических процедур. Таким образом, можно производить оценку того, насколько для выбранной области активности подходит человек, и прогнозировать его успешность (Barbot et al, 2016). Исследуя креативный потенциал с помощью пяти переменных при решении заданий из областей рисования и литературного творчества, авторы проводили диагностику двух ключевых творческих мыслительных процессов: дивергентно-исследовательскую модель мышления, ассоциируемую с гибкостью, дивергентным мышлением и конативными компонентами (открытость новому опыту, внутренняя мотивация и ориентация на задачу), и конвергентно-объединяющую модель, ассоциируемую с ассоциативным мышлением, операциями сравнения, комбинирования и конативными компонентами (толерантность к неопределенности, риск, мотивация достижения). Работа по расширению области применения моделей, например на решение социальных проблем, только началась (Ibid.). Однако важными для интересующей нас проблемы креативности и девиантности 
являются следующие следствия. Во-первых, использование одной методики для диагностики недостаточно, чтобы выявить креативный потенциал. Во-вторых, для разработки решения какой-либо задачи и его реализации требуется наличие разных личностных характеристик и черт.

Анализ результатов исследований позволяет выделить особенности социально-креативной личности, т.е. такой личности, которая находит эффективные и новые решения проблем в социальном взаимодействии: неформальное лидерство; высокие значения эмоционального интеллекта, когнитивной и аффективной эмпатии и поиска новизны; низкий уровень зависимости от вознаграждения; гибкие моральные границы; макиавеллизм, умение манипулировать другими для достижения собственных целей; разумное сочетание эгоизма и альтруизма (Мешкова, Ениколопов, 2016а). Кроме того, социально креативная личность не только может находить решение и реализовывать его, но и оказывать влияние на окружающих, изменяя их установки и поведение (Дубов, Петровский, 1987), а также ценности (Мешкова, Ениколопов, 2016а). Как видно, не все характеристики «вписываются» в модели, разработанные Б. Барбот с соавт. Однако представляется, что без учета всех переменных вряд ли возможно составить профиль антисоциальной креативности и объяснить творческое мышление, направленное на причинение вреда и ущерба, особенно в тех случаях, когда речь идет о преступной группе, лидер которой является социально-креативным человеком. Здесь стоит заметить, что методы, используемые при лабораторной диагностике социальной креативности, направлены на выявление креативного потенциала и, как правило, не дают представления о поведении индивида в реальных ситуациях.

Если говорить о реализации креативного потенциала, то исследователи полагают, что если создать для этого определенные условия, то человек его обязательно реализует (Caroff, Lubart, 2012; Hester et al., 2012). Как показывают исследования, такие негативные для креативности факторы, как угроза, давление, ограничения времени, страх смерти и состояние ностальгии, в некоторых случаях могут оказывать позитивное влияние на креативность (Мешкова, 2015). Так, в ситуации угрозы для организации испытуемые более креативны в том случае, если нормы организации коллективистские (Walton, Kemmelmeier, 2012). Процедура активации мыслей о смерти вызывает рост невербальной креативности у испытуемых с низкой потребностью в структуре (предпочтение порядка, простоты и предсказуемости, восприятие мира в черно-белых тонах) (Routledge, Jacob, 2012) и при фокусировании на общественной задаче (цель - сделать полезное для общества) (Routledge et al., 2008). В состоянии ностальгии люди вспоминают и реконструируют содержание эпизодической памяти, что активирует определенные участки мозга, ответственные за креативные решения, и, в свою очередь, приводит к повышению показателей при исследовании креативности (Ye et al., 2013). В других экспериментах было показано, что нечестное поведение позволяет человеку почувствовать себя свободным от правил и норм, что также приводит к росту креативности (Gino, Wiltermuth, 2014). Кроме того, угрожающий социальный контекст повышает генерирование креативных идей, поскольку в ситуации 
угрозы приходится решать проблему именно новым и нетривиальным способом (Mayer, Mussweiler, 2011).

Bce, о чем говорилось выше, касается изучения влияния ситуации на предметную креативность. Что же касается антисоциальной креативности, то таких исследований в психологии практически нет. Существует исследование, результаты которого демонстрируют, что подростки создают вебсайты, наносящие вред (проактивная виртуальная агрессия), в условиях анонимности и уверенности в том, что не будут обнаружены (Law et al., 2012). Также было показано, что творческие способности могут с успехом применяться для причинения вреда другим людям в ситуации реакции на нанесенную ими обиду (Hao et al., 2016).

Таким образом, скрытость, анонимность, месть за причиненную обиду характеристики ситуаций, в которых с большей вероятностью могут реализовываться антисоциально направленный творческий потенциал и агрессия (Ениколопов, Мешкова, 2008).

\section{Антисоциальная креативность и девиантное поведение}

Основная проблема в изучении антисоциальной креативности состоит в том, чтобы выявить параметры, способствующие продуцированию негативных творческих идей и их реализации в девиантном поведении, что в конечном итоге можно свести к взаимодействию вида задачи и средств ее выполнения.

Исследователи полагают, что основой антисоциальной креативности является агрессия (Ениколопов и др., 2014). Если человек импульсивен, а ситуация провоцирует нанесение вреда, то имеющаяся у него неосознаваемая агрессия проявляется в зловредной креативности. Так, Д. Харрис и Р. Рейтер-Палмон в лабораторных условиях получили независимые от социальной желательности результаты связи ситуационных характеристик - анонимности и мести - с продуцированием креативных решений, приносящих вред обидчикам (Harris, Reiter-Palmon, 2015). Выявленная зависимость позволяет предположить, что люди с высоким уровнем агрессии при определенных обстоятельствах могут использовать свой креативный потенциал для нанесения вреда и реализовать его в агрессивном поведении. Р. Чавез-Еакле и ее коллеги показали связь высокого уровня креативности с высокими значениями поиска новизны и настойчивости и низким значением избегания вреда (Chavez-Eakle et al, 2006). Такие же показатели темпераментальных характеристик, а также высокое значение враждебности, генерализованной в картине мира, были выявлены в группе скинхедов (Мешкова, Ениколопов, 2010). Таким образом, враждебность как личностная черта может стать медиатором связи креативного потенциала и девиантного поведения, как и эмоциональный интеллект (Archer, Coyne, 2005). Например, социальная агрессия (причинение вреда социальному статусу) связана с низким уровнем эмоционального интеллекта (Cleverley et al., 2012), а большое количество зловредных идей коррелирует с низким эмоциональным интеллектом испытуемых (Harris et al., 2013). 
Однако понятно, что одно дело придумывать вредные идеи, а другое - воплощать их в жизнь.

Исследования криминального поведения показывают, что преступники являются психопатами (Атаджыкова, Ениколопов, 2016), обладающими такими ассоциируемыми с креативностью характеристиками, как лживость, манипуляция, отсутствие угрызений совести, низкий уровень саморегуляции, неспособность взять на себя ответственность за собственные поступки, импульсивность, гнев и эгоцентризм (Cropley, Cropley, 2011), что также дает возможность предположить в основе связи криминального поведения и креативности низкие значения эмпатии и эмоционального интеллекта. Остается невыясненным, чей креативный потенциал (собственный или чужой) реализуется в криминальных действиях, но очевидно, что и разработчики, и исполнители склонны оправдывать собственное поведение и любые средства для достижения собственных целей (Мешкова, Ениколопов, 2016б).

Взаимодействие целей и способов достижения находится в основе теории креативной девиантности С. Майнемелис, посвященной анализу неконформного поведения служащего на рабочем месте. Теория объясняет феномен продолжения работы над новой идеей при запрете руководства заниматься ею. Под креативной девиантностью С. Майнемелис понимает достижение легитимных целей нелегитимными способами. Описываемое явление рассматривается в рамках организационного менеджмента при наличии в организации скудных ресурсов и отвергнутых идей. Причем, как отмечает С. Майнемелис, в данном случае результат этого процесса неопределенный, поскольку предугадать заранее, будет ли он положительным или отрицательным, невозможно, но, как правило, креативный продукт будет радикальным, и важно, что в основе процесса находится легитимная цель или решение легитимной задачи (Mainemelis, 2010). Заслуга данного автора состоит в том, что его теория креативности включает цель, способы и условия ее реализации, а также результаты процесса. Хотя теория предназначена для решения проблем в менеджменте, на наш взгляд, область ее применения может быть расширена при введении дополнительных характеристик, касающихся модальности параметров.

Дело в том, что С. Майнемелис исходил из представления о девиантности как о модели поведения, проявляющегося в нарушении только тех норм, которые приняты в отдельной группе/организации, при этом не затрагивающей норм нравственности и морали социума, а также законы государства.

В то же время девиантность, нарушающая законы и социальные ожидания, не должна игнорироваться, как и креативность/творческие способности, направленные на достижение деструктивных целей. На основании анализа исследований и подходов зарубежных авторов мы предлагаем комплексную модель креативности и девиантности, учитывающую ресурсы разработчика и исполнителей, модальность целей и способов достижения целей, ситуационные условия, стимулирующие разработку, результаты, а также мишени вреда или ущерба (собственность/имущество или человек/люди) (см. рисунок 1). 
Комплексная модель креативности и девиантности (личность, цель, условия, средства, результат и мишень вреда)

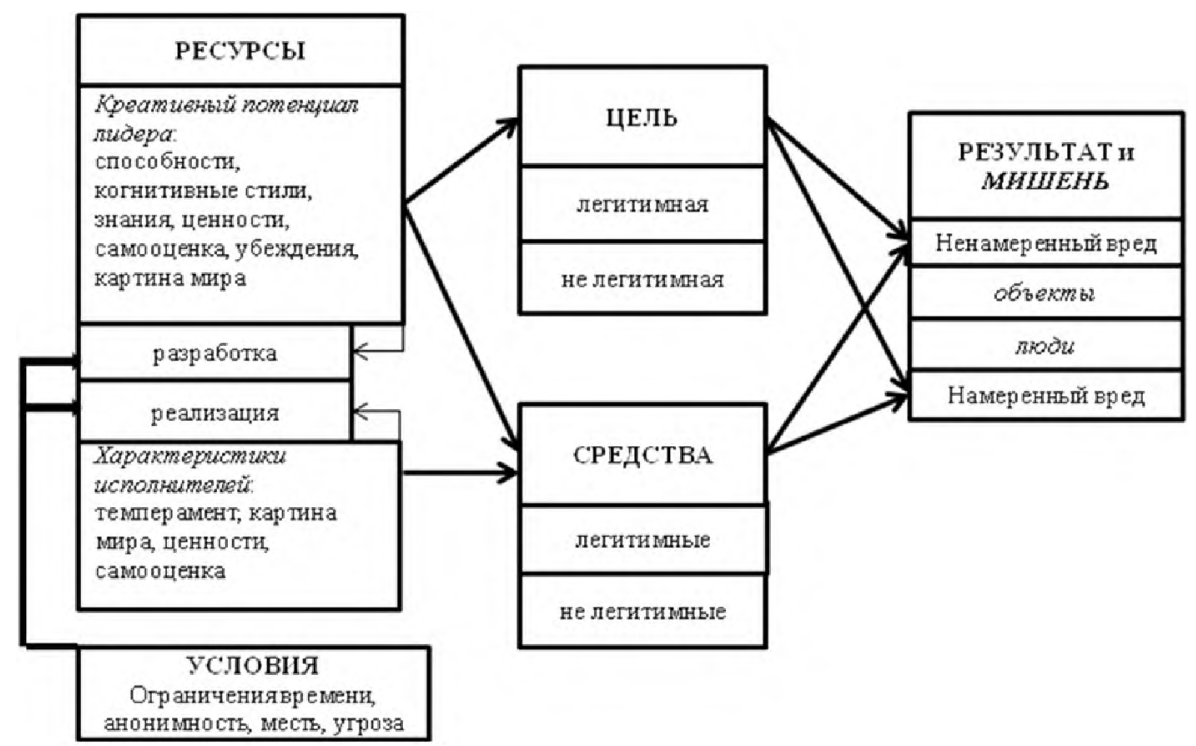

\section{Комплексная модель креативности и девиантности}

Особенность модели состоит в том, что ее можно применять для анализа и изучения антисоциальной креативности как отдельных индивидов, так и групп. Модель позволяет выделить и концептуализировать четыре вида креативности. Негативная креативность - решение легитимной задачи легитимными способами, в ходе которых обнаружился ненамеренно нанесенный вред людям или объектам. Креативная девиантность - решение легитимной задачи нелегитимными способами, нанесшими вред другим людям. Антисоциальная/асоциальная креативность - решение нелегитимной задачи нелегитимными или деструктивными способами, нанесшими вред другим людям. Девиантная креативность - решение нелегитимной задачи легитимными способами, в результате которого был нанесен вред собственности.

Поясним используемые в модели параметры

Ресурсы - креативный потенциал; включает в себя комплекс характеристик, необходимых для разработки решений задачи/цели. Представляется, что придумать нелегитимные цели может любой индивид, но решиться на их выполнение могут только те, кто обладает соответствующими характеристиками.

Условия - ситуативные характеристики, которые выступают триггерами для разработки креативных идей и способов их реализации. Разумеется, 
ситуации, стимулирующие лидера разрабатывать идеи, и условия реализации этих идей разные.

Цель - задача, которую решает лидер группы или отдельный индивид. В рамках антисоциальной креативности, например, задачи в террористической деятельности и задачи, стоящие перед мошенниками, совершенно разные. Мы полагаем, что цели актуализируются ценностями.

Способы - оригинальные стратегии и способы решения задачи. В рамках антисоциальной креативности реализация цели всегда осуществляется деструктивными способами и девиантными формами поведения. Сами деструктивные способы могут быть оригинальными и эффективными. Месть за измену и месть за занятое место на парковке могут осуществляться а) одинаковыми способами, приносящими вред обидчику, хотя и были вызваны разными ситуативными триггерами, или б) разными способами в зависимости от ситуации: явно или анонимно.

Результат и мишень вреда - достижение цели, сопровождающееся нанесением вреда или ущерба. Особенность антисоциальной креативности состоит в том, что решение задачи всегда сопровождается нанесением вреда/ущерб́а окружающим людям и конкретному человеку.

Разумеется, необходимы исследования для уточнения характеристик разработчиков и исполнителей, а также способов достижения целей и условий, способствующих как разработке (например, перспективна ли для изучения зависть), так и реализации креативных идей. На настоящий момент относительно антисоциальной креативности имеются следующие представления, которые нуждаются в дальнейшей эмпирической проверке:

1. Нелегитимные цели могут опосредоваться ситуацией угрозы ценностям.

2. Требуются дифференцированные ресурсы для разработки нелегитимной цели и осуществления ее нелегитимными или деструктивными способами.

Проверка сформулированных гипотез позволит заполнить имеющиеся лакуны информацией об особенностях характеристик креативных преступников и ситуаций, в которых реализуется креативный потенциал, без знания чего затруднительны профилактика и превентивные мероприятия.

\section{Литература}

Атаджькова, Ю. А., Ениколопов, С. Н. (2016). Проблемы концепта психопатии в современной отечественной и зарубежной психологии. Психологическая наука и образование psyedu.nu, 8(1), 114-127. doi:10.17759/psyedu.2016080111

Дубов, И.Г., Петровский, В. А. (1987). Перестройка личностных структур учащихся при персонализации личности педагога. В кн. А. В. Петровский (ред.), Психология развивающейся лииности (с. 173-191). М.: Просвещение.

Ениколопов, С. Н. (2010). Актуальные проблемы исследования агрессивного поведения. Прикладная юридическая психология, 2, 37-47.

Ениколопов, С. Н., Кузнецова, Ю. М., Чудова, Н. В. (2014). Агрессия обыденной жизни. М.: РОСсПЭН. 
Ениколопов, С. Н., Мешкова, Н. В. (2008). Психологические аспекты «преступлений ненависти». Криминология: вчера, сегодия, завтра, 2(15), 63-74.

Мешкова, Н. В. (2015). Современные зарубежные исследования креативности: социально-психологический аспект. Социальная психология и общество, 6(2), 8-21.

Мешкова, Н. В., Ениколопов, С. Н. (2010). Предубежденность в контексте свойств личности. Психологический журнал, 4, 35-46.

Мешкова, Н. В., Ениколопов С. Н. (2016а). Направления исследований креативности в социальном взаимодействии. Вопросы психологии, 4, 118-128.

Мешкова, Н. В., Ениколопов, С. Н. (2016б). О психологических исследованиях асоциальной креативности. Психологиеские исследования, 9(50). Режим доступа: http://psystudy.ru

Ссылки на зарубежные истоиники см. в разделе References после англоязыиного блока.

Мешкова Наталья Владимировна - доцент, кафедра теоретических основ социальной психологии, факультет социальной психологии, ФГБОУ ВО «Московский государственный психолого-педагогический университет», кандидат психологических наук.

Сфера научных интересов: социальная психология, психология одаренности, психология креативности, юридическая психология.

Контакты: nmeshkova@yandex.ru

Ениколопов Сергей Николаевич - заведующий отделом медицинской психологии, Федеральное государственное бюджетное научное учреждение «Научный центр психического здоровья», кандидат психологических наук.

Сфера научных интересов: клиническая психология, юридическая психология, криминальная психология, психология юмора.

Контакты: enikolopov@mail.ru

\title{
Creativity and Deviance: Communication and Interaction
}

\author{
N.V. Meshkova ${ }^{a}$, S.N. Enikolopov ${ }^{b}$ \\ ${ }^{a}$ Moscow State University of Psychology and Education, 29, Sretenka Str., Moscow, 127051, Russian \\ Federation \\ ${ }^{5}$ The Mental Health Research Center, 34 Kashirskoe Highway, Moscow, 115522, Russian Federation
}

\begin{abstract}
We analyze the theories and concepts of creativity and creative potential. We discuss the personal characteristics that will contribute to malevolent creativity that causes harm to other people. Features of the socially-creative person are given: informal leadership; high values of emotional intelligence, cognitive and affective empathy and the search for novelty; low level of dependence on remuneration; flexible moral boundaries; Machiavellianism, the ability to manipulate others to achieve their own goals; a reasonable combination of selfishness and altruism. Approaches to understanding the creative potential and assessment of its components are considered, as well as personal and situational characteristics that promote the realization of creative potential for harming other people. As for personal characteristics that contribute to the
\end{abstract}


realization of creative potential in deviant behavior, hostility and emotional intelligence are allocated for further research. Based on the theory of creative deviance by C. Mainemelis, we proposed complex model of creativity and deviance. The model combines such parameters as creative potential, characteristics of the performers, purpose, conditions and ways to achieve the goal, the result. The model takes into consideration the modality of the objectives, methods and results of the creative process, and the target of harm. The specifics of the model is that it can be used for analysis and study of antisocial creativity of individuals and groups. Within the model there are 4 kinds of creativity. We defined them "deviant creativity", "anti-social/asocial creativity", "negative creativity" and "creative deviance".

Keywords: creativity, deviance, creative deviance, antisocial creativity, integrated model of creativity and deviance.

\section{References}

Archer, J., \& Coyne, S. M. (2005). An integrated review of indirect, relational, and social aggression. Personality and Social Psychology Review, 9, 212-230.

Atadjikova, Yu. A., \& Enikolopov, S. N. (2016). Problems of psychopathy concept in the modern domestic and foreign psychology. Psikhologicheskaya Nauka i Obrazovanie [Psychological Science and Education psyedu.nu], 8(1), 114-127. doi:10.17759/psyedu.2016080111 (in Russian)

Baer, J. (2010). Is creativity domain specific? In J. C. Kaufmann \& R. J. Sternberg (Eds.), The Cambridge handbook of creativity (pp. 321-341). New York: Cambridge University Press.

Barbot, B., Besançon, M., \& Lubart, T. (2016). The generality-specificity of creativity: Exploring the structure of creative potential with EPoC. Learning and Individual Differences, 52(1), 178-187. doi:10.1016/j.lindif.2016.06.005

Caroff, X., \& Lubart, T. (2012). Multidimensional approach to detecting creative potential in managers. Creativity Research Joumal, 24(1), 13-20. doi:10.1080/10400419.2012.652927

Chavez-Eakle, R. A., Lara, M. C., \& Cruz-Fuentes, C. (2006). Personality: A possible bridge between creativity and psychopathology? Creativity Research Journal, 18, 27-38.

Cleverley, K., Szatmari, P., Vaillancourt, T., Boyle, M., \& Lipman, E. (2012). Developmental trajectories of physical and indirect aggression from late childhood to adolescence: Sex differences and outcomes in emerging adulthood. Joumal of the American Academy of Child and Adolescent Psychiatry, 51, 1037-1051.

Corazza, G. E. (2016). Potential originality and effectiveness: the dynamic definition of creativity. Creativity Research Joumal, 28(3), 258-267. doi:10.1080/10400419.2016.1195627

Cropley, A. J., \& Cropley, D. H. (2011). Creativity and lawbreaking. Creativity Research Journal, 23(4), 313-320. doi:10.1080/10400419.2011.621817

Dubov, I. G, \& Petrovsky, V. A. (1987). Perestroika lichnostnyh struktur uchashchihsya pri personalizatsii lichnosti pedagoga [Reorganization of students' personality structures with personalization of teacher's personality]. In A. V. Petrovsky (Ed.), Psikhologiya razvivanushcheisya lichnosti [Psychology of developing personality]. (pp. 173-191). Moscow: Prosveshhenie. (in Russian)

Enikolopov, S. N. (2010). Aktual'nye problemy issledovaniya agressivnogo povedeniya [Live issues of aggressive behavior study]. Prikladnaya Yuridicheskaya Psikhologiya, 2, 37-47. (in Russian)

Enikolopov, S. N., Kuznetsova, Iu. M., \& Chudova, N.V. (2014). Agressiya o obydennoi zhizni [Agression in everyday life]. Moscow: ROSSPEN. (in Russian) 
Enikolopov, S. N., \& Meshkova, N. V. (2008). Psikhologicheskie aspekty "prestuplenii nenavisti" [Psychological issues of hate crimes]. Kriminologiya: Vchera, Segodnya, Zavtra, 2(15), 64-74. (in Russian)

Enikolopov, S. N., \& Meshkova, N. V. (2010). Prejudicialness in the context of personality characteristics. Psikhologicheskii Zhumal, 31(4), 35-46. (in Russian)

Gino, F., \& Wiltermuth, S. (2014). Evil genius? How dishonesty can lead to greater creativity. Psychological Science, 25(4), 973-981.

Hao, N., Tang, M., Yang, J., Wang, Q., \& Runco, M. A. (2016). A new tool to measure malevolent creativity: The malevolent creativity behavior scale. Frontiers in Psychology, 7, 682. doi: $10.3389 /$ fpsyg.2016.00682

Harris, D. J., \& Reiter-Palmon, R. (2015). Fast and furious: The influence of implicit aggression, premeditation, and provoking situations on malevolent creativity. Psychology of Aesthetics, Creativity, and the Arts, 9(1), 54-64. doi:10.1037/a0038499

Harris, D. J., Reiter-Palmon, R., Kaufman, J. C. (2013). The effect of emotional intelligence and task type on malevolent creativity. Psychology of Aesthetics, Creativity, and the Arts, 7, 237-244. doi: $10.1037 / \mathrm{a} 0032139$

Hennessey, B. A., \& Amabile, T. M. (2010). Creativity. Annual Review of Psychology, 61, 569-598. doi:10.1146/annurev.psych.093008.100416

Hester, K. S., Robledo, I. C., \& Barrett, J. D. (2012). Causal analysis to enhance creative problem-solving: performance and effects on mental models. Creativity Research Joumal, 24(2-3), 115-133. doi:10.1080/10400419.2012.677249

Julmi, C., \& Scherm, E. (2015). The domain-specificity of creativity: Insights from new phenomenology. Creativity Research Joumal, 27(2), 151-159. doi:10.1080/10400419.2015.1030310

Kharkhurin A. V. (2014). Creativity. 4in1: Four-criterion construct of creativity. Creativity Research Joumal, 26(3), 338-352. doi:10.1080/10400419.2014.929424

Law, D. M., Shapka, J. D., Domene, J. F., \& Gagne, M. H. (2012). Are cyberbullies really bullies? An investigation of reactive and proactive online aggression. Computers in Human Behavior, 28, 664-672.

Mainemelis, C. (2010). Stealing fire: Creative deviance in the evolution of new ideas. Academy of Management Review, 35, 558-578.

Mayer, J., \& Mussweiler, T. (2011). Suspicious spirits, flexible minds: When distrust enhances creativity. Journal of Personality and Social Psychology, 101(6), 1262-1277.

Meshkova, N. V. (2015). Modern foreign research in creativity: The social psychological aspect. Sotsial'naya Psikhologiya i Obshchestvo [Social psychology and society], 6(2), 8-21. (in Russian)

Meshkova, N. V., \& Enikolopov, S. N. (2016a). The directions of creativity research in social interaction. Voprosy Psikhologii, 4, 118-128. (in Russian)

Meshkova, N. V., \& Enikolopov, S. N. (2016b). On psychological research of antisocial creativity. Psikhologicheskie Issledovaniya, 9(50). Retrieved from http://psystudy.ru (in Russian)

Rhodes, M. (1961). An analysis of creativity. Phi Beta Kappen, 42, 305-310.

Routledge, C., Arndt, J., Vess, M., \& Sheldon, K. (2008). The life and death of creativity: The effects of self versus other-oriented behavior on creative expression after mortality salience. Motivation and Emotion, 32, 331-338.

Routledge, C., \& Jacob, J. J. (2012). The creative spark of death: The effects of mortality salience and personal need for structure on creativity. Motivation and Emotion, 36, 478-482. doi:10.1007/s11031-011-9274-1 
Walton, A. P., \& Kemmelmeier, M. (2012). Creativity in its social context: The interplay of organizational norms, situational threat, and gender. Creativity Research Joumal, 24(2-3), 208-219. doi:10.1080/10400419.2012.677345

Westwood, R., \& Low, D. R. (2003). The multicultural muse: Culture, creativity and innovation. Intemational Joumal of Cross Cultural Management, 3, 235-259. doi:10.1177/14705958030032006

Ye, S., Ngan, R. Y. L., \& Hui, A. N. N. (2013). The state, not the trait, of nostalgia increases creativity. Creativity Research Joumal, 25(3), 317-323. doi:10.1080/10400419.2013.813797

Natalya V. Meshkova - associate professor, the Chair of Theoretical Foundations of Social Psychology, Moscow State University of Psychology \& Education, Ph.D.

Research area: social psychology, psychology of giftedness, psychology of creativity, forensic psychology.

E-mail: nmeshkova@yandex.ru

Sergei N. Enikolopov - head, the Department of Medical Psychology, Mental Health Research Center, Ph.D.

Research area: clinical psychology, forensic psychology, victimology, psychology of humor.

E-mail: enikolopov@mail.ru 